\title{
Phase Angle as an Objective and Predictive Factor of Radiotherapy-induced Changes in Body Composition of Male Patients With Head and Neck Cancer
}

\author{
TERESA MAŁECKA-MASSALSKA ${ }^{1}$, TOMASZ POWRÓZEK ${ }^{1}$, MONIKA PRENDECKA $^{1}$, RADOSŁAW MLAK $^{1}$, \\ GRZEGORZ SOBIESZEK ${ }^{2}$, WOJCIECH BRZOZOWSKI ${ }^{3}$ and ANNA BRZOZOWSKA ${ }^{4}$ \\ ${ }^{1}$ Department of Human Physiology, Medical University of Lublin, Lublin, Poland; \\ ${ }^{2}$ Department of Cardiology, 1st Military Clinical Hospital with the Outpatient Clinic, Lublin, Poland; \\ ${ }^{3}$ Department of Cardiology, Medical University Lublin, Lublin, Poland; \\ ${ }^{4}$ St. John of Dukla Lublin Region Cancer Center, Lublin, Poland
}

\begin{abstract}
Background: Unfavorable changes in body composition are frequent among patients with head and neck cancer (HNC). Unfortunately, in daily clinical practice, there is a lack of reliable diagnostic tools for predicting changes in body composition in individuals following radiotherapy $(R T)$. Among non-invasive tools, bioelectrical impedance analysis (BIA) seems to be most promising. One BIA parameter, the phase angle (PA), reflects condition of various body cells and their mass in detail. Materials and Methods: Using BIA, the body composition was measured prior to and after RT in 52 male patients with HNC.PA derived from BIA prior to RT was tested as a predictor of body composition changes developing during RT. Results: Patients with low PA had a greater than 9.3-fold higher chance of body mass index (BMI) reduction below $18.5 \mathrm{~kg} / \mathrm{m}^{2}$ and over 5.9-fold and 4.2-fold higher chance of lean mass and fat mass reduction after therapy end compared with patients with a high PA value. PA values demonstrated significant diagnostic accuracy for detection of fat-free mass, lean mass and BMI reduction in the study group [area under the curve $(A U C)=0.781,0.774$ and 0.786, respectively]. Conclusion: PA prior to $R T$ is a useful marker for selection of individuals with HNC who are at a high risk of unfavorable changes in body composition.
\end{abstract}

This article is freely accessible online.

Correspondence to: Tomasz Powrózek, PhD, Physiology Department, Medical University of Lublin Radziwillowska Street 11, 20-080 Lublin, Poland. E-mail: tomaszpowrozek@gmail.com; Professor Teresa Małecka-Massalska, Physiology Department, Medical University of Lublin Radziwillowska Street 11, 20-080 Lublin, Poland. E-mail: t.malecka@gmail.com

Key Words: Head and neck cancer, bioimpedance, phase angle, body composition, radiotherapy.
In addition to surgical intervention, the majority of patients with head and neck cancer (HNC) undergo radiotherapy (RT) to improve treatment outcomes. Despite a significant number of patients benefiting from RT due to noticeable reduction of tumor mass and an increase in the survival time, unfortunately, side-effects of applied therapy are frequently reported $(1,2)$. In patients with $\mathrm{HNC}$, side-effects including oral mucositis, xerostomia and loss of appetite are the most serious events, and lead to reduction of energy intake and eventually to critical nutritional problems, such as loss of body weight and serious changes in body composition. Unfortunately, the nutritional deficits in addition to the sideeffects of RT have a negative impact on patient quality of life, therapy outcomes and overall survival (3-6). Most patients with HNC undergoe RT develop malnutrition, which in predisposed individuals can lead to cachexia. It is generally believed that reduction of both body mass and body mass index (BMI) can predict malnutrition and cachexia $(7,8)$. Taking into consideration recent findings, both malnutrition and cachexia are now known to be more complex than previously supposed. In selected individuals with cancer, although the results of anthropometric measurements are usually normal, they are actually either malnourished or cachectic. Malnutrition and cachexia can indeed be masked by the parallel loss of body weight or BMI reduction and water retention or change in the ratio between the muscle and the fat tissue in a large number of patients with cancer. Assessment of body composition can only reveal nutritional deficits. Detailed body composition data reliably reflect changes in a patient's metabolism, which is altered by increased muscle proteolysis and lipolysis of fat tissue. As an effect of these metabolic changes, nutritional deficit is demonstrated by the reduction of the mass of various body tissues. This emphasizes the complexity of syndromes related to malnutrition $(6,9,10)$. Based on the 
above, assessment of body composition, instead of BMI and loss of body weight, should be a better objective tool for the evaluation of nutritional deficits.

Due to its reliability, bioelectrical impedance analysis (BIA) seems to be the most precise among the tools available for evaluating both nutritional status and body composition of patients with cancer. This method is already used in patients suffering from kidney diseases, lung disorders, AIDS and heart failure to assess their nutritional status $(11,12)$. The utility of BIA has been proven in the assessment of body composition of patients with cancer. Interestingly, the first signs of malnutrition detected by BIA may precede development of cachexia by several months. In patients with HNC, parameters derived from BIA are used for evaluation of nutritional status and objectively reflect the condition of different body tissues, especially fat and lean mass (13). Among parameters derived from BIA, the phase angle (PA) is considered the most promising factor referring to the entire body condition. Recent literature reports have demonstrated its utility in the assessment of body composition in various types of human cancer, emphasizing its predictive and prognostic value (14-17). The majority of studies have investigated PA as a parameter for distinguishing malnourished patients from cachectic or to well-nourished ones. However, there is a lack of data concerning the role of PA for the prediction of changes in body composition developing as a result of irradiation. Nowadays, selection of individuals at a high risk of malnutrition due to RT is usually made based on clinical factors and anthropometry.

In the present study, we demonstrate a novel approach to PA analysis using its value as a potential predictive marker of RT-induced changes in body composition of HNC individuals. The assessment of PA before the application of the RT can serve as an objective factor allowing patients at the highest risk of unfavorable body composition changes due to irradiation to identified. Appropriate identification of predisposed patients might enable early nutritional intervention for prevention of malnutrition and cachexia.

\section{Materials and Methods}

Patients and clinical data. The research project was approved by the Bioethical Commission of the Medical University of Lublin (approval no.: KE-0254/232/2014). Prior to the study, all patients signed informed consent forms. The study protocol was followed at the Department of Oncology of the Medical University of Lublin (in the time period 2014-2015).

Fifty-two male patients with HNC in stages I-IV [according to the seventh edition of the TNM staging (18)] of the disease were enrolled in this study. The following inclusion criteria were used: i) Male patients $\geq 18$ years old; ii) presence of primary tumor in the head and neck area; iii) patients who underwent complete RT regimen ( 7 cycles); iv) Eastern Cooperative Oncology Group World Health Organization (ECOG-WHO) performance status $\leq 1$; v) absence of anemia and kidney, heart or kidney diseases. The
Table I. Characteristics of the study group.

\begin{tabular}{|c|c|c|}
\hline Factor & & Study group \\
\hline Gender & Male & 52 \\
\hline \multirow[t]{3}{*}{ Age } & Median (range), years & $63(42-81)$ \\
\hline & $>63$ Years, $\mathrm{n}(\%)$ & $25(48.1 \%)$ \\
\hline & $\leq 63$ Years, $\mathrm{n}(\%)$ & $27(51.9 \%)$ \\
\hline \multirow{2}{*}{$\begin{array}{l}\text { Histopathological } \\
\text { diagnosis, } \mathrm{n}(\%)\end{array}$} & Squamous cell carcinoma & $48(92.3 \%)$ \\
\hline & Other & $4(7.7 \%)$ \\
\hline \multirow[t]{2}{*}{ Tumor location, n (\%) } & Oropharynx & $15(28.8 \%)$ \\
\hline & Hypopharynx & $37(71.2 \%)$ \\
\hline \multirow[t]{4}{*}{ T-Stage, n (\%) } & $\mathrm{T} 1$ & $2(3.9 \%)$ \\
\hline & $\mathrm{T} 2$ & $9(17.3 \%)$ \\
\hline & $\mathrm{T} 3$ & $13(25 \%)$ \\
\hline & $\mathrm{T} 4$ & $28(53.8 \%)$ \\
\hline \multirow[t]{4}{*}{ N-Stage, n (\%) } & No & $16(30.8 \%)$ \\
\hline & $\mathrm{N} 1$ & $6(11.5 \%)$ \\
\hline & $\mathrm{N} 2$ & $26(50 \%)$ \\
\hline & N3 & $4(7.7 \%)$ \\
\hline \multirow[t]{3}{*}{ M-Stage, n (\%) } & Mx & $2(3.9 \%)$ \\
\hline & M0 & $49(94.2 \%)$ \\
\hline & M1 & $1(1.9 \%)$ \\
\hline \multirow[t]{5}{*}{ Disease stage, $\mathrm{n}(\%)$} & I & $2(3.9 \%)$ \\
\hline & III & $10(19.2 \%)$ \\
\hline & IVA & $35(67.3 \%)$ \\
\hline & IVB & $1(1.9 \%)$ \\
\hline & IVC & $4(7.7 \%)$ \\
\hline \multirow[t]{3}{*}{ Type of treatment, n (\%) } & Surgery+RT & $29(55.8 \%)$ \\
\hline & Surgery+CRT & $14(26.9 \%)$ \\
\hline & RT alone & $9(17.3 \%)$ \\
\hline Performance status, n (\%) & 1 & $52(100 \%)$ \\
\hline \multirow[t]{2}{*}{ Alcohol consumption, $\mathrm{n}(\%)$} & Yes & $22(42.3 \%)$ \\
\hline & No & $30(57.7 \%)$ \\
\hline \multirow[t]{4}{*}{ Smoking status, n (\%) } & Smoker & $42(80.8 \%)$ \\
\hline & Non-smoker & $10(19.2 \%)$ \\
\hline & Current smoker & $35(83.3 \%)$ \\
\hline & Former smoker & $7(16.7 \%)$ \\
\hline \multirow[t]{2}{*}{ Parenteral nutrition, n (\%) } & Yes & $7(13.5 \%)$ \\
\hline & No & $45(86.5 \%)$ \\
\hline Weight, kg & Mean \pm SD & $67.13 \pm 11.79$ \\
\hline BMI, $\mathrm{kg} / \mathrm{m}^{2}$ & Mean \pm SD & $23.71 \pm 4.54$ \\
\hline \multirow[t]{3}{*}{ SGA, n (\%) } & A & $5(9.6 \%)$ \\
\hline & $\mathrm{B}$ & $31(59.6 \%)$ \\
\hline & $\mathrm{C}$ & $16(30.8 \%)$ \\
\hline \multirow[t]{3}{*}{ NRS, n (\%) } & 2 & $29(55.8 \%)$ \\
\hline & 3 & $15(28.8 \%)$ \\
\hline & 4 & $8(15.4 \%)$ \\
\hline Total protein, $\mathrm{g} / \mathrm{l}$ & Mean \pm SD & $6.71 \pm 0.53$ \\
\hline Albumin, g/l & Mean \pm SD & $3.34 \pm 0.26$ \\
\hline Pre-albumin, g/dl & Mean \pm SD & $0.20 \pm 0.08$ \\
\hline Transferrin, g/l & Mean \pm SD & $2.60 \pm 0.57$ \\
\hline
\end{tabular}

BMI: Body mass index; NRS: nutritional risk screening; RT: radiotherapy; CRT: chemoradiotherapy; SGA: subjective global assessment.

exclusion criteria were as follows: i) Patients with incomplete treatment regimen ( $<7$ cycles of RT); ii) patients with limb amputation or prosthesis; iii) presence of metal implants, cardioverter or pacemaker; iv) immobilized patients or patients 
Table II. Differences in body composition and nutritional features between patients according to phase angle (PA). Data are the mean $\pm S D$.

\begin{tabular}{|c|c|c|c|c|}
\hline \multirow[t]{2}{*}{ Factor } & \multirow[b]{2}{*}{ Time point } & \multicolumn{2}{|c|}{$\mathrm{PA}$} & \multirow{2}{*}{$\begin{array}{c}\text { Between-group } \\
p \text {-Value }\end{array}$} \\
\hline & & High & Low & \\
\hline \multirow[t]{2}{*}{ Weight, kg } & Before RT & $68 \pm 10.42$ & $67 \pm 13.15$ & 0.205 \\
\hline & After RT & $65 \pm 8.71$ & $58 \pm 9.75$ & 0.016 \\
\hline$p$-Value & & 0.033 & $<0.001$ & \\
\hline \multirow[t]{2}{*}{ BMI, $\mathrm{kg} / \mathrm{m}^{2}$} & Before RT & $25.04 \pm 3.88$ & $22.87 \pm 4.41$ & 0.041 \\
\hline & After RT & $23.49 \pm 3.30$ & $18.70 \pm 3.36$ & 0.005 \\
\hline$p$-Value & & 0.136 & $<0.001$ & \\
\hline \multirow[t]{2}{*}{$\mathrm{FM}, \mathrm{kg}$} & Before RT & $22.44 \pm 7.32$ & $18.54 \pm 8.21$ & 0.942 \\
\hline & After RT & $20.72 \pm 7.38$ & $16.05 \pm 5.76$ & 0.088 \\
\hline$p$-Value & & 0.855 & 0.001 & \\
\hline \multirow{2}{*}{$\mathrm{FM}, \%$} & Before RT & $29.52 \pm 8.34$ & $29.94 \pm 8.01$ & 0.243 \\
\hline & After RT & $28.66 \pm 8.08$ & $25.41 \pm 5.90$ & 0.318 \\
\hline$p$-Value & & 0.465 & 0.011 & \\
\hline \multirow[t]{2}{*}{ FFM, $\mathrm{kg}$} & Before RT & $48.44 \pm 5.52$ & $46.05 \pm 9.08$ & 0.342 \\
\hline & After RT & $46.96 \pm 6.05$ & $40.92 \pm 7.54$ & 0.047 \\
\hline$p$-Value & & 0.071 & 0.143 & \\
\hline \multirow[t]{2}{*}{ FFM, $\%$} & Before RT & $70.62 \pm 8.39$ & $69.95 \pm 8.80$ & 0.263 \\
\hline & After RT & $71.14 \pm 8.10$ & $74.77 \pm 5.95$ & 0.307 \\
\hline$p$-Value & & 0.447 & 0.040 & \\
\hline \multirow[t]{2}{*}{ Lean mass, $\mathrm{kg}$} & Before RT & $50.06 \pm 6.41$ & $40.10 \pm 9.42$ & 0.08 \\
\hline & After RT & $44.44 \pm 5.51$ & $41.23 \pm 6.76$ & 0.041 \\
\hline$p$-Value & & 0.010 & 0.294 & \\
\hline \multirow[t]{2}{*}{ FFMI, $\mathrm{kg} / \mathrm{m}^{2}$} & Before RT & $17.33 \pm 2.36$ & $14.53 \pm 2.90$ & 0.007 \\
\hline & After RT & $15.28 \pm 2.14$ & $14.17 \pm 2.02$ & 0.007 \\
\hline$p$-Value & & 0.012 & 0.261 & \\
\hline \multirow[t]{2}{*}{ TP, $\mathrm{g} / \mathrm{l}$} & Before RT & $6.71 \pm 0.59$ & $6.70 \pm 0.49$ & 0.734 \\
\hline & After RT & $6.42 \pm 0.70$ & $6.42 \pm 0.59$ & 0.755 \\
\hline$p$-Value & & 0.082 & 0.610 & \\
\hline \multirow[t]{2}{*}{ Albumin, g/l } & Before RT & $3.36 \pm 0.26$ & $3.30 \pm 0.19$ & 0.654 \\
\hline & After RT & $3.14 \pm 0.51$ & $3.31 \pm 0.43$ & 0.121 \\
\hline$p$-Value & & & 0.125 & 0.523 \\
\hline Transferrin, g/l & Before RT & $2.60 \pm 0.61$ & $2.60 \pm 0.58$ & 0.341 \\
\hline Pre-albumin, g/dl & Before RT & $0.20 \pm 0.08$ & $0.20 \pm 0.10$ & 0.114 \\
\hline \multirow[t]{4}{*}{ SGA, n (\%) } & A & $1(20 \%)$ & $4(80 \%)$ & 0.184 \\
\hline & $\mathrm{B}+\mathrm{C}$ & $26(55.3 \%)$ & $21(44.7 \%)$ & \\
\hline & $A+B$ & $18(50 \%)$ & $18(50 \%)$ & 0.768 \\
\hline & $\mathrm{C}$ & $9(56.3 \%)$ & $7(43.7 \%)$ & \\
\hline \multirow[t]{4}{*}{ NRS, n (\%) } & 2 & $13(44.8 \%)$ & $16(55.2 \%)$ & 0.278 \\
\hline & 3 and 4 & $14(60.9 \%)$ & $9(39.1 \%)$ & \\
\hline & 2 and 3 & $26(59.1 \%)$ & $18(40.9 \%)$ & 0.022 \\
\hline & 4 & $1(12.5 \%)$ & $7(87.5 \%)$ & \\
\hline
\end{tabular}

SGA and NRS were assessed prior to RT. BMI: Body mass index; FM: fat mass; FFM: fat-free mass; FFMI: fat-free mass index; NRS: nutritional risk screening; SGA: subjective global assessment; TP: total protein; RT: radiotherapy.

unable to lay still or supine. Baseline characteristics of patients are presented in Table I.

For evaluation of the stage of disease, the seventh edition of TNM classification was used (18). All patients were irradiated with the use of the intensity-modulated radiotherapy technique (daily dose of $2 \mathrm{~Gy}$; total dose: 66-70 Gy). Detailed data were collected from all patients including demographic (age), tumor-related (histological type, location TNM, stage), clinical (performance status, type of treatment), nutritional evaluation [body weight, BMI, Subjective Global Assessment (SGA), Nutritional Risk Score (NRS), total protein, albumin, pre-albumin and transferrin] and other (smoking status and alcohol consumption). SGA and NRS were evaluated by a medical doctor before commencement of RT (based on the physical examination and the features of medical record). According to nutritional status, patients were divided into three groups: SGA-A (well-nourished), SGA-B (moderately malnourished) and SGA-C (severely malnourished).

BIA measurements. BIA measurement was performed before and after the commencement of RT. ImpediMed bioimpedance analysis SFB7 BioImp v1.55 equipment was used for BIA (Pinkenba, QLD, Australia). All measurements were performed while the patients 
in vivo $33: 1645-1651(2019)$

Table III. Factors significantly affecting the risk of unfavorable body composition characteristics in the study group.

\begin{tabular}{|c|c|c|c|c|c|}
\hline & \multirow[b]{2}{*}{ Factor } & \multicolumn{2}{|c|}{ Univariate analysis } & \multicolumn{2}{|c|}{ Multivariate analysis } \\
\hline & & OR $(95 \% \mathrm{CI})$ & $p$-Value & OR $(95 \% \mathrm{CI})$ & $p$-Value \\
\hline $\mathrm{BMI}<24.9 \mathrm{~kg} / \mathrm{m}^{2}$ & Low PA & $3.57(0.95-13.46)$ & 0.032 & $4.76(0.91-21.71)$ & 0.040 \\
\hline $\mathrm{BMI}<18.5 \mathrm{~kg} / \mathrm{m}^{2}$ & Low PA & $7.73(1.68-35.47)$ & 0.009 & $9.30(1.94-105.44)$ & 0.010 \\
\hline \multirow[t]{2}{*}{ FFMI $<14.9 \mathrm{~kg} / \mathrm{m}^{2}$} & $\mathrm{NRS}>3$ & $0.43(0.12-1.48)$ & 0.179 & $16.47(0.68-304.6)$ & 0.045 \\
\hline & Disease stage IV & $3.06(0.68-13.74)$ & 0.129 & $10.79(0.93-125.6)$ & 0.047 \\
\hline \multirow[t]{3}{*}{ Lean mass $<44.2 \mathrm{~kg}$} & Low PA & $3.51(1.08-11.39)$ & 0.037 & $5.87(0.94-36.80)$ & 0.039 \\
\hline & High TNF $\alpha$ & $3.47(1.11-11.67)$ & 0.032 & $3.78(1.20-12.73)$ & 0.028 \\
\hline & SGA B or C & $3.62(0.81-5.56)$ & 0.438 & $27.6(0.98-766.7)$ & 0.041 \\
\hline \multirow[t]{3}{*}{ FFM $<44.7 \mathrm{~kg}$} & Low PA & $1.56(0.46-5.22)$ & 0.047 & $2.09(0.76-7.11)$ & 0.127 \\
\hline & Age $>63$ years & $2.37(0.87-6.48)$ & 0.148 & $6.78(0.82-55.9)$ & 0.045 \\
\hline & Smoking: Yes & $11.20(1.25-100.3)$ & 0.031 & $18.0(1.21-267.0)$ & 0.036 \\
\hline \multirow[t]{3}{*}{$\mathrm{FM}<16 \mathrm{~kg}$} & Low PA & $0.89(0.27-2.97)$ & 0.853 & $21.2(1.17-383.8)$ & 0.039 \\
\hline & Smoking: Yes & $3.45(1.60-19.38)$ & 0.153 & $4.15(1.00-17.13)$ & 0.040 \\
\hline & Late toxicity & $7.23(2.56-42.87)$ & 0.089 & $5.13(0.92-28.64)$ & 0.042 \\
\hline \multirow[t]{2}{*}{ Weight loss $>5 \%$} & $\mathrm{NRS}>3$ & $5.70(1.45-22.35)$ & 0.008 & $19.43(1.57-241.1)$ & 0.021 \\
\hline & Smoking: Yes & $0.11(0.01-0.99)$ & 0.049 & $0.47(0.09-1.34)$ & 0.324 \\
\hline
\end{tabular}

BMI: Body mass index; CI: confidence intervaI; FM: fat mass; FFM: fat-free mass; LM: lean mass; FFMI: fat-free mass index; NRS: nutritional risk screening; PA: phase angle; OR: odds ratio; SGA: subjective global assessment; TNF $\alpha$ : tumor necrosis factor $\alpha$.

were lying supine on a bed (arms not touching the torso and legs apart) with use of standard electrodes (tetra-polar). Electrodes were attached to the hand and foot on the right side of the patient. For each study participant, the conditions of BIA were similar. All BIA measurements were collected at the same time of day (morning) and on an empty stomach, and the intake of food and beverages (including alcohol consumption) was prohibited for 12 hours before the measurements. Secondly, prior to the BIA measurements, patients lay on the bed for at least 5 minutes allowing compensation of the fluid level in the body. Resistance (R) and reactance $(\mathrm{Xc})$ values were measured (at $50 \mathrm{kHz}$ ) three times, and mean values for each patient were calculated. The value of PA was automatically obtained from the equipment (based on the arctangent ratio $\mathrm{Xc}$ : $\mathrm{R}$ and transformation of radians to degrees previous result multiplied by $180^{\circ} / \pi$ ). The following parameters concerning body composition were derived from BIA: BMI, fat mass (FM), fat-free mass (FFM) and lean mass. Fat-free mass index (FFMI) was calculated using the following mathematical formula: $\operatorname{FFMI}\left(\mathrm{kg} / \mathrm{m}^{2}\right)=\mathrm{FFM}(\mathrm{kg}) /[\text { height }(\mathrm{m})]^{2}$.

Statistical analysis. Collected data were analyzed with use of MedCalc software (v15.8; MedCalc, Ostend, Belgium). Student's ttest (parametric) was used for comparisons of continuous variables (weight, BMI, BIA and biochemical parameters). Continuous data comparisons were performed depending on categorized or dichotomized variables (PA: high/low; RT status: before/after). Univariate and multivariate logistic regression models with odds ratio (OR) calculation were used for evaluation of clinicodemographic and nutritional factors in the risk of reduction of BMI, FM, FFM, lean mass and FFMI. Receiver operating characteristic curve (ROC) analysis with area under the curve (AUC) calculation was used for evaluation of diagnostic accuracy of PA for detecting changes in body composition parameters. Results with $p<0.05$ were considered as statistically significant.

\section{Results}

According to PA value (mean: $4.61 \pm 0.69^{\circ}$ ) patients were divided into following two groups - group with high PA (PA values over the mean score) and group with low PA (PA values below the mean score) level. In 27 (51.9\% of the study group) patients with HNC, we found high PA (group mean: $4.98 \pm 0.37^{\circ}$ ), whereas in 25 cases $(48.1 \%$ of patients), a low PA was noted (group mean: $4.36 \pm 0.58^{\circ}$ ). PA values did not depend on clinicodemographic characteristics of the studied patients (all $p>0.05$ ).

Firstly, we compared both body composition parameters and nutritional features between patients qualified of two study groups according to PA value. Male patients with HNC with low PA demonstrated worse nutritional characteristics compared with patients with a high PA, and the most significant differences were observed after the commencement of RT. At that time, in contrast to those with high PA, patients with low PA had significantly lower body weight $(58 \pm 9.75 v s .65 \pm 8.71 \mathrm{~kg} ; p=0.016)$, BMI $(18.70 \pm 3.36$ vs. $\left.23.49 \pm 3.30 \mathrm{~kg} / \mathrm{m}^{2} ; p=0.005\right)$, FFM $(40.92 \pm 7.54 v s$. $46.96 \pm 6.05 \mathrm{~kg} ; p=0.047)$, lean mass $(41.23 \pm 6.76 \mathrm{vs}$. $44.44 \pm 5.51 \mathrm{~kg} ; p=0.041)$ and FFMI (14.17 $\pm 2.02 v s$. $\left.15.28 \pm 2.14 \mathrm{~kg} / \mathrm{m}^{2} ; p=0.007\right)$. Moreover, notable differences concerning BMI (22.87 \pm 4.41 vs. 25.04 $\pm 3.88 ; p=0.041)$ and FFMI $\left(14.53 \pm 2.90\right.$ vs. $\left.17.33 \pm 2.36 \mathrm{~kg} / \mathrm{m}^{2} ; p=0.007\right)$ between the study groups were recorded before the commencement of RT. We also observed that patients with low PA more often had a higher malnutrition according to NRS scale compared with those with high PA $(p=0.022)$ (Table II). 
Małecka-Massalska et al: PA Predicts Body Composition Changes in Patients with HNC

Table IV. Diagnostic accuracy of phase angle (PA) for the detection of body composition changes in male patients after radiotherapy.

\begin{tabular}{|c|c|c|c|c|c|c|c|}
\hline & \multirow[t]{2}{*}{$\mathrm{FM}<16 \mathrm{~kg}$} & \multirow[t]{2}{*}{ FFM $<44.7 \mathrm{~kg}$} & \multirow[t]{2}{*}{ FFMI $<14.9 \mathrm{~kg} / \mathrm{m}^{2}$} & \multirow[t]{2}{*}{$\mathrm{LM}<44.2 \mathrm{~kg}$} & \multicolumn{2}{|c|}{ Weight loss } & \multirow[t]{2}{*}{ BMI $<18.5 \mathrm{~kg} / \mathrm{m}^{2}$} \\
\hline & & & & & $>5 \%$ & $>10 \%$ & \\
\hline Sensitivity (\%) & 60 & 52.6 & 64.1 & 60 & 60.9 & 50 & 74 \\
\hline Specificity (\%) & 84.6 & 82.9 & 73.1 & 95.7 & 70 & 77.8 & 60 \\
\hline AUC & 0.781 & 0.632 & 0.673 & 0.774 & 0.585 & 0.537 & 0.786 \\
\hline PA cut-off & $4.42^{\circ}$ & $4.42^{\circ}$ & $4.68^{\circ}$ & $4.42^{\circ}$ & $4.58^{\circ}$ & $4.44^{\circ}$ & $4.58^{\circ}$ \\
\hline$p$-Value & $<0.001$ & 0.146 & 0.231 & $<0.001$ & 0.352 & 0.713 & 0.002 \\
\hline
\end{tabular}

AUC: Area under the curve; BMI: body mass index; FM: fat mass; FFM: fat-free mass; FFMI: fat-free mass index; LM: lean mass.

Secondly, in both studied groups we compared changes in body composition developing during the therapy period (before $v s$. after RT). For patients with high PA, a decrease in body composition measurements was observed especially for body weight (reduction from 68 to $65 \mathrm{~kg}$; $p=0.033$ ), lean mass (reduction from 50.06 to $44.44 \mathrm{~kg} ; p=0.010$ ) and FFMI (reduction from 17.33 to $15.28 \mathrm{~kg} / \mathrm{m}^{2}, p=0.012$ ). However, the most unfavorable changes in body composition developed in patients with low PA. In those patients, reduction of body weight was more substantial in contrast to patients with high PA ( 9 vs. $3 \mathrm{~kg}$ ). Moreover, we noted a significant decrease in BMI, FM (kg), FM (\%) and FFM (\%) $(p<0.001,0.001,0.011$ and 0.040 , respectively) in those with low PA (Table II).

The subsequent goal of the study was to assess the impact of PA on the risk of changes in body composition developing in male patients with HNC during the RT period. The impact of the PA value on both body composition and nutritional parameters is presented in Table III using cut-offs for FM, FFM, lean mass and FFMI based on their mean values. Both univariate and multivariate analyses showed a low value of PA to be a factor negative affecting BMI, lean mass and FM. In the univariate analysis, the following ORs were achieved: 3.57 for BMI $<24.5 \mathrm{~kg} / \mathrm{m}^{2}, 7.73$ for BMI $<18.5 \mathrm{~kg} / \mathrm{m}^{2}$, and 3.51 for lean mass $<44.2 \mathrm{~kg}$, respectively. Introducing all clinical features into the multivariate analysis, we found that individuals with low PA had over 4-fold and 9-fold higher risk of BMI reduction below $24.5 \mathrm{~kg} / \mathrm{m}^{2}$ and $18.5 \mathrm{~kg} / \mathrm{m}^{2}$, respectively. A low PA was also found to be a factor unfavorably affecting the risk of reduction of lean mass $(\mathrm{OR}=5.87)$ and $\mathrm{FM}(\mathrm{OR}=4.15)$.

Finally, using the ROC analysis, we investigated the diagnostic accuracy of PA for detecting changes in body composition developing as a result of RT. In Table IV, we summarize the diagnostic accuracy of PA, including test sensitivity, specificity, AUC score and cut-off point for detecting changes in particular body composition parameters.

PA demonstrated significant diagnostic accuracy for detection of FM reduction below $16 \mathrm{~kg}$ (sensitivity of $60 \%$ and specificity of $84.6 \%$; $\mathrm{AUC}=0.781$ ), lean mass reduction below $44.2 \mathrm{~kg}(60 \%$ sensitivity and $95.7 \%$ specificity; $\mathrm{AUC}=0.774$ ) and $\mathrm{BMI}$ reduction below $18.5 \mathrm{~kg} / \mathrm{m}^{2}$ (sensitivity of $74 \%$ and specificity of $60 \%$; AUC $=0.786$ ) (Figure 1).

\section{Discussion}

Changes in body composition developing in patients with HNC undergoing RT have both significant and negative impact on the patient's condition, including nutritional status, quality of life, treatment outcomes and overall survival. Several methods, such as computed tomography, bone densitometry dual-energy x-ray absorptiometry (DEXA) and BIA have been applied for the assessment of body composition. Among these methods, BIA seems to be most useful because it can be applied in an out-patient setting at the bed, the examination is short, and the devices are portable and cheaper in contrast to advanced imaging methods. The utility of BIA for the evaluation of body composition was proven in several studies, including the recent study of Tang et al., which enrolled patients with different types of cancer. They noted the reduction of BMI in all study participants after the commencement of RT. Moreover, in those with HNC, the progressive reduction of muscle mass was observed after the fourth week of RT, and was most significant after therapy end (reduction from $46.88 \mathrm{~kg}$ to $40.86 \mathrm{~kg}$ ). For all body measurements, BIA was used and allowed highlighting of patients at a risk of malnutrition (19).

Currently, only few BIA parameters have been evaluated widely in patients with cancer, of which PA was studied the most frequently. PA provides detailed characteristics of the cell state and the overall condition of a patient's body, and therefore it is considered an objective parameter reliably reflecting the nutritional condition of the examined patient. The utility of PA as a tool for the assessment of the nutritional status of patients with cancer has been confirmed in many studies that enrolled patients suffering from various tumor types $(14,15,17,20)$. Based on the results achieved from the studies on patients with $\mathrm{HNC}$, a low value of PA is currently considered an unfavorable factor affecting a patient's nutritional status and survival. This 

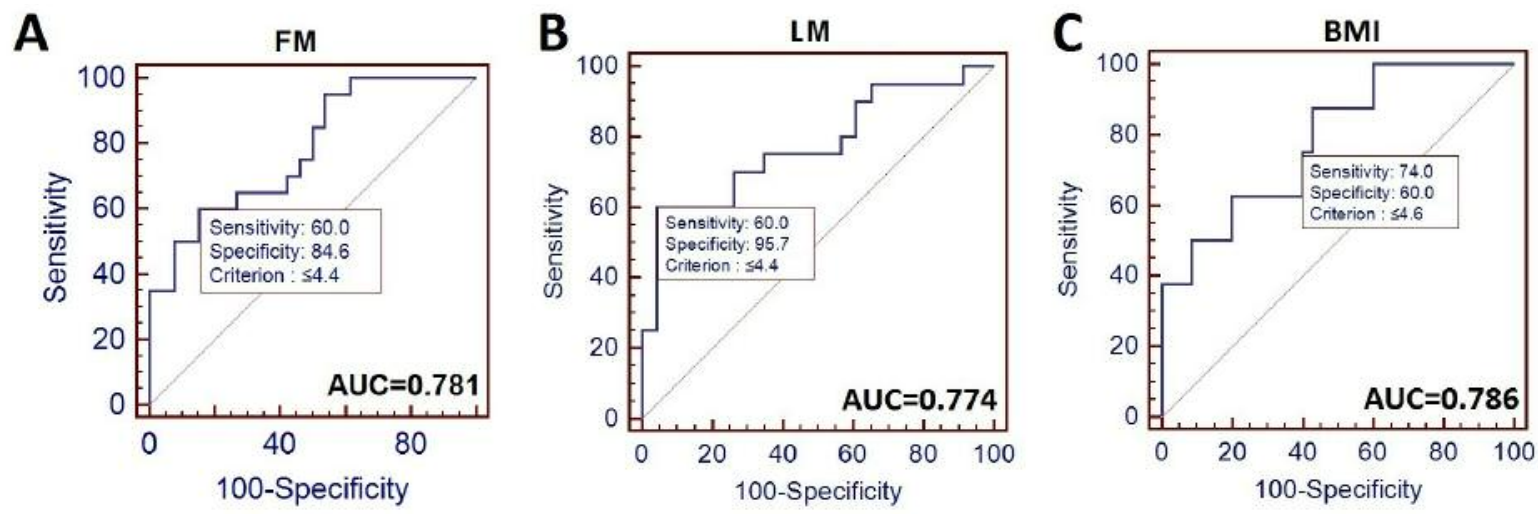

Figure 1. Diagnostic accuracy of phase angle (PA) for distinguishing patients with head and neck cancer with fat mass $(F M) \leq 16 \mathrm{~kg}$ from those with $F M>16 \mathrm{~kg}(A)$, those with lean mass $(L M) \leq 44.1 \mathrm{~kg}$ from cases with $L M 44.1 \mathrm{~kg}(B)$, and those with body mass index $(B M I) \leq 18.5 \mathrm{~kg} / \mathrm{m}^{2} \mathrm{from}$ those with normal BMI (C). AUC: Area under the curve.

phenomenon was also confirmed by the results of our study. Patients with HNC with a low PA had significantly worse characteristics of parameters referring to body composition after the commencement of RT compared with patients with high PA. In the study of Paixão et al., a positive correlation was found between PA and BMI, as well as body weight in patients with cancer $[\mathrm{r}=0.273 \quad(p=0.032)$ and $\mathrm{r}=0.413$ $(p=0.022)$, respectively] (21). Similar results were noted by Lundberg et al., PA positively correlated with BMI ( $\mathrm{r}=0.562$, $p<0.01)$, FFMI $(\mathrm{r}=0.467, p<0.01)$ and fat mass index $(\mathrm{r}=0.411$, $p<0.01$ ) (22). Our results are in accordance with these studies. We also found a positive correlation between PA and BMI $(\mathrm{r}=0.562, p=0.002)$. Moreover, PA correlated with lean mass, FFMI and FFM measured after the end of RT [ $\mathrm{r}=0.295$ $(p=0.045), \mathrm{r}=0.372 \quad(p=0.014)$, and $\mathrm{r}=0.352 \quad(p=0.020)$, respectively]. The study of Małecka-Massalska et al. demonstrated that well-nourished patients with HNC had a significantly higher PA (mean: 5.25 ${ }^{\circ}$ ) compared with malnourished (mean: $4.73^{\circ}$ ) ones. A PA cut-off of $4.73^{\circ}$ had $80 \%$ sensitivity and $56.7 \%$ specificity for the detection of malnutrition diagnosed by SGA in those patients (23). On the other hand, Stegel et al. observed that low PA increased the risk of malnutrition and cachexia in patients with HNC treated with RT ( $\mathrm{OR}=1.71 ; p=0.018)$. However, PA failed to show any predictive value for cachexia (AUC $=0.578, p>0.05$ ) (24). We noted a similar tendency in our study, PA failed to predict malnutrition defined by loss of $5 \%$ body mass (AUC $=0.585$, $p=0.352$ ). Despite that, in our study set, PA demonstrated a significant diagnostic accuracy for the detection of reduction of FM, lean mass and BMI in the study group after therapy end (AUC $=0.781,0.774$ and 0.786 , respectively).

Currently, there is a lack of studies that have investigated the predictive value of PA as a factor for identifying patients at risk of unfavorable changes in body composition due to irradiation. Firstly, we found that patients with low PA prior to RT had a significantly worse BMI and FM after the commencement of RT in contrast to those with high PA. Moreover, patients with a low PA had over 9.3-fold higher risk of BMI reduction below $18.5 \mathrm{~kg} / \mathrm{m}^{2}$ and over 5.9 -fold and 4.2-fold higher risk of lean mass and FM reduction after therapy end compared with patients with high PA.

\section{Conclusion}

PA derived from BIA seems to be a useful predictive marker for selection of individuals the $\mathrm{HNC}$ at high risk of development of unfavorable RT-induced changes in body composition. Patients with low PA prior to RT are more susceptible to significant weight loss, BMI, FM and FFM reduction during the RT period. Moreover, patients with low PA have a significantly higher risk of muscle mass reduction (lean mass) after RT in contrast to those with high PA values. PA also serves as a potential diagnostic tool for the detection of reduction of BMI, lean mass and FM in patients with HNC. Based on the above, such patients might be identified and be earlier scheduled to nutritional intervention and supportive care, therefore avoiding unfavorable changes in body composition and benefiting more from therapy. The major limitations of our study are the low number of studied HNC cases, the retrospective analysis, and lack of PA utility for prediction of either malnutrition or cachexia, however, similar observations were noted by others.

\section{Funding}

This research received no external funding.

\section{Conflicts of Interest}

The Authors declare no conflict of interest in regard to this study. 


\section{Authors' Contributions}

Study idea and design: TMM and TP; Statistical analysis: TP; Sample collection: AB; Writing and editing: MP, RM, WB, GS.

\section{References}

1 Ottosson S, Zackrisson B, Kjellén E, Nilsson P and Laurell G: Weight loss in patients with head and neck cancer during and after conventional and accelerated radiotherapy. Acta Oncol 52(4): 711-718, 2013. PMID: 23106176. DOI: 10.3109/0284 186X.2012.731524

2 Langius JA, van Dijk AM, Doornaert P, Kruizenga HM, Langendijk JA, Leemans CR, Weijs PJ and Verdonck-de Leeuw IM: More than $10 \%$ weight loss in head and neck cancer patients during radiotherapy is independently associated with deterioration in quality of life. Nutr Cancer 65(1): 76-83, 2013. PMID: 23368916. DOI: 10.1080/01635581.2013.741749

3 Mortensen HR, Overgaard J, Specht L, Overgaard M, Johansen J, Evensen JF, Andersen LJ, Andersen E and Grau C: Prevalence and peak incidence of acute and late normal tissue morbidity in the DAHANCA $6 \& 7$ randomised trial with accelerated radiotherapy for head and neck cancer. Radiother Oncol 103(1): 69-75, 2012 PMID: 22398313. DOI: 10.1016/j.radonc. 2012. 01.002

4 Jacquelin-Ravel $\mathrm{N}$ and Pichard C: Clinical nutrition, body composition and oncology: a critical literature review of the synergies. Crit Rev Oncol Hematol 84: 37-46, 2012. PMID: 22522184. DOI: 10.1016/j.critrevonc.2012.02.001

5 Gorenc M, Kozjek NR and Strojana P: Malnutrition and cachexia in patients with head and neck cancer treated with (chemo)radiotherapy. Rep Pract Oncol Radiother 20(4): 249-258, 2015. PMID: 26109912. DOI: 10.1016/j.rpor.2015.03.001

6 Alshadwi A, Nadershah M, Carlson ER, Young LS, Burke PA and Daley BJ: Nutritional considerations for head and neck cancer patients: A review of the literature. J Oral Maxillofac Surg 71: 1853 1860, 2013. PMID: 23845698. DOI: 10.1016/ j.joms.2013.04.028

7 Lønbro S, Petersen GB, Andersen JR and Johansen J: Prediction of critical weight loss during radiation treatment in head and neck cancer patients is dependent on BMI: Support Care Cancer 24(5): 2101-2109, 2016. PMID: 26553031. DOI: 10.1007/ s00520-015-2999-8

8 Silander E, Nyman $\mathbf{J}$ and Hammerlid E: An exploration of factors predicting malnutrition in patients with advanced head and neck cancer. Laryngoscope 123(10): 2428-2434, 2013. PMID: 23918730. DOI: 10.1002/lary.23877

9 Tisdale MJ: Mechanisms of cancer cachexia. Physiol Rev 89: $381-$ 410, 2009. PMID: 19342610. DOI: 10.1152/physrev.00016.2008

10 Couch ME, Dittus K, Toth MJ, Willi MS, Guttridge DC and George JR: Cancer cachexia update in head and neck cancer: Definitions and diagnostic features. Head Neck 37: 594-604, 2015. PMID: 24415363. DOI: 10.1002/hed.23599

11 Barbosa-Silva MC and Barros AJ: Bioelectrical impedance analysis in clinical practice: a new perspective on its use beyond body composition equations. Curr Opin Clin Nutr Metab Care 8: 311-317, 2005. PMID: 15809535.

12 Mulasi U, Kuchnia AJ, Cole AJ and Earthman CP: Bioimpedance at the bedside: current applications, limitations, and opportunities. Nutr Clin Pract 30(2): 180-193, 2015. PMID: 25613832. DOI: $10.1177 / 0884533614568155$

13 Grundmann O, Yoon SL and Williams JJ: The value of bioelectrical impedance analysis and phase angle in the evaluation of malnutrition and quality of life in cancer patients - a comprehensive review. Eur J Clin Nutr 69(12): 1290-1297, 2015. PMID: 26220573. DOI: $10.1038 /$ ejen.2015.126

14 Gupta D, Lis CG, Dahlk SL, King J, Vashi PG, Grutsch JF and Lammersfeld CA: The relationship between bioelectrical impedance phase angle and subjective global assessment in advanced colorectal cancer. Nutr J 7: 19, 2008. PMID: 185905 54. DOI: 10.1186/1475-2891-7-19.

15 Małecka-Massalska T, Smoleń A and Morshed K: Tissue electrical properties in head and neck tumors before and after surgery: Preliminary observations. Indian J Cancer 51: 209-213, 2014. PMID: 25494106. DOI: 10.4103/0019-509X.146717

16 Władysiuk MS, Mlak R, Morshed K, Surtel W, Brzozowska A and Małecka-Massalska T: Phase angle is considered to be a nutritional indicator in patients with head and neck cancer in detecting malnutrition. Curr Oncol 23(5): e481-e487, 2016. PMID: 25859939. DOI: 10.1007/s00405-015-3626-5

17 Ozorio GA, Barão K and Forones NM: Cachexia stage, patientgenerated subjective global assessment, phase angle, and handgrip strength in patients with gastrointestinal cancer. Nutr Cancer 69(5): 772-779, 2017. PMID: 28524706. DOI: 10.1080/01635581.2017.1321130

18 Deschler DG, Moore MG and Smith RV: Quick Reference Guide to TNM Staging of Head and Neck Cancer and Neck Dissection Classification, Edition. Alexandria, VA: American Academy of Otolaryngology-Head and Neck Surgery Foundation, 2014. Available from: https://www.entnet.org/sites/ default/files/Neck Dissection_QuickRefGuide_highresFINAL.pdf (Last accessed July 4, 2019)

19 Tang PL, Wang HH, Lin HS, Liu WS, Chen LM and Chou FH: Body composition early identifies cancer patients with radiotherapy at risk for malnutrition. J Pain Symptom Manage 55(3): 864-871, 2018. PMID: 29051113. DOI: 10.1016/ j.jpainsymman.2017.10.005

20 Schütte K, Tippelt B, Schulz C, Röhl FW, Feneberg A, Seidensticker R, Arend J and Malfertheiner P: Malnutrition is a prognostic factor in patients with hepatocellular carcinoma (HCC). Clin Nutr 34(6): 1122-1127, 2015. PMID: 25434576. DOI: 10.1016/j.clnu.2014.11.007

21 Paixão EM, Gonzalez MC and Ito MK: A prospective study on the radiation therapy associated changes in body weight and bioelectrical standardized phase angle. Clin Nutr 34(3): 496-500, 2015. PMID: 24953772. DOI: 10.1016/j.clnu.2014.05.012

22 Lundberg M, Nikander P, Tuomainen K, Orell-Kotikangas H, Mäkitie A: Bioelectrical impedance analysis of head and neck cancer patients at presentation. Acta Otolaryngol 137(4): 417-420, 2017. PMID: 28079435. DOI: 10.1080/00016489. 2016.1266510

23 Małecka-Massalska T, Mlak R, Smoleń A and Morshed K: Bioelectrical impedance phase angle and subjective global assessment in detecting malnutrition among newly diagnosed head and neck cancer patients. Eur Arch Otorhinolaryngol 273(5): 12991305, 2016. PMID: 25859939. DOI: 10.1007/ s00405-015-3626-5

24 Stegel P, Kozjek NR, Brumen BA and Strojan P: Bioelectrical impedance phase angle as indicator and predictor of cachexia in head and neck cancer patients treated with (chemo)radiotherapy. Eur J Clin Nutr 70(5): 602-606, 2016. PMID: 26908426. DOI: 10.1038/ejen.2016.13

Received May 27, 2019

Revised June 28, 2019

Accepted July 4, 2019 